2012 ACR

2016 ACR/

$98.90 \%$

$88.00 \%$

0.561

Specificity

2002 AECG

2012 ACR

2016 ACR/

$93.80 \%$

$71.30 \%$

$96.30 \%$

EULAR

between NS involvement and atherosclerotic stroke (OR 10.4, 95\% CI 2.8-38.5), ear disease (OR 2.1, 95\% Cl 1.1-4.2) and myopathy (OR 6.5, $95 \% \mathrm{Cl} 1.3-31,6)$. Patients with NS involvement had higher probability of being treated with glucocorticoids (OR $3.3,95 \% \mathrm{Cl} 1.5-7.2$ ) and cyclophosphamide (OR 6.8, 95\% Cl 1.5-31).

Conclusion: $15 \%$ of patients with pSS develope NS involvement that is associated with atherosclerotic stroke, ear disease and myopathy.

REFERENCE:

[1] Vitali C. et al. Ann Rheum Dis 2002; 61:554

AECG: American European Consensus Group criteria;

Conclusion: In our population, the ACR criteria showed the highest sen sitivity, while the ACR/EULAR criteria showed the highest specificity, showing a moderate level of agreement. Despite the validation of these criteria, its application in real life tests its performance according to the population studied.

\title{
REFERENCES:
}

[1] Tsuboi, H., et al. (2017). Comparison of performance of the 2016 ACREULAR classification criteria for primary Sjögren's syndrome with other sets of criteria in Japanese patients. Annals of the Rheumatic Diseases, 76(12), 1980?1985. https://doi.org/10.1136/annrheumdis-2016-210758.

Disclosure of Interests: None declared

DOI: 10.1136/annrheumdis-2019-eular.6626

\section{THU0258 NERVOUS SYSTEM INVOLVEMENT IN PRIMARY SJÖGREN'S SYNDROME}

Jose Luis Andreu ${ }^{1}$, Carlos Sánchez-Piedra ${ }^{2}$, Monica Fernandez Castro ${ }^{1}$, Victor Martinez Taboada ${ }^{3}$, Alejandro Olive ${ }^{4}$, Jose Rosas ${ }^{5}$, Raúl Menor-Almagro ${ }^{6}$, Beatriz Rodriguez Lozano ${ }^{7}$, Ángel García-Aparicio ${ }^{8}$, Francisco J López-Longo ${ }^{9}$, Sara Manrique Arija ${ }^{10}$, Jesús Alberto García Vadillo ${ }^{11}$, Susana Gil ${ }^{12}$, Ruth López González ${ }^{13}$, J. Narváez ${ }^{14}$, Carles Galisteo ${ }^{15}$, Jorge Juan Gonzalez Martin ${ }^{16}$, M E Ruiz ${ }^{17}$, Iñigo Rúa-Figueroa ${ }^{18}$, Oscar Illera ${ }^{19}$, Lurdes Romani ${ }^{20}$, Sheila Melchor ${ }^{21}$, Begoña Moreira ${ }^{22}$, Enrique Raya ${ }^{23}$, Jose M Pego-Reigosa ${ }^{24}$, Natalia Cid Boza ${ }^{25}$, Enrique Judez ${ }^{26}$, Clara Moriano ${ }^{27}$, Vicente Torrente ${ }^{28}$, Héctor Corominas ${ }^{29}$, Blanca Garcia-Magallon ${ }^{30}$, Carlos Guillén-Astete ${ }^{31}$, Ivan Castellvi ${ }^{32}$, Cristina Bohórquez ${ }^{33}$, Javier Loricera ${ }^{34}$, Joaquín Belzunegui ${ }^{35} .{ }^{1} \mathrm{H}$. U. Puerta de Hierro Majadahonda, Majadahonda, Spain; ${ }^{2}$ Sociedad Española de Reumatología, Madrid, Spain; ${ }^{3}$ H.U. Marqués de Valdeilla, Santander, Spain; ${ }^{4}$ H.U. Germans Trias i Pujol, Badalona, Spain; ${ }^{5}$ H.U. Marina Baixa, Villajoyosa, Spain; ${ }^{6}$ H.U. Jerez de la Frontera, Jerez de la Frontera, Spain; ${ }^{7}$ H.U. de Canarias, Santa Cruz de Tenerife, Spain; ${ }^{8}$ H.U. Virgen de la Salud, Toledo, Spain; ${ }^{9}$ H.G.U. Gregorio Marañón, Madrid, Spain; ${ }^{10}$ H.U. Carlos Haya, Málaga, Spain; ${ }^{11}$ H.U. La Princesa, Madrid, Spain; ${ }^{12}$ H.U. de Alicante, Alicante, Spain; ${ }^{13}$ H.U. Virgen de la Concha, Zamora, Spain; ${ }^{14}$ H.U. Bellvitge, Barcelona, Spain; ${ }^{15}$ H.U. Parc Tauli, Sabadell, Spain; ${ }^{16}$ H.U. Madrid Norte Sanchinarro, Madrid, Spain; ${ }^{17}$ H.U. Basurto, Bilbao, Spain; ${ }^{18}$ H.U. Doctor Negrín, Las Palmas, Spain; ${ }^{19}$ H.U. Infanta Sofía, San Sebastián de los Reyes, Spain; ${ }^{20} \mathrm{H}$.U. Virgen de las Nieves, Granada, Spain; ${ }^{21} \mathrm{H}$. U. 12 de Octubre, Madrid, Spain; ${ }^{22}$ H.U. Sierrallana, Sierrallana, Spain; ${ }^{23}$ H.U. San Cecilio, Granada, Spain; ${ }^{24}$ H.U. do Mexoeiro, Vigo, Spain; ${ }^{25}$ H.U. Valme, Sevilla, Spain; ${ }^{26}$ H.U. de Albacete, Albacete, Spain; ${ }^{27}$ C.A.H. de Leon, Leon, Spain; ${ }^{28}$ H.U. L'Hospitalet, Barcelona, Spain; ${ }^{29}$ H.U. Sant Joan Despí Moisès Broggi, Barcelona, Spain; ${ }^{30}$ H.U. Miguel Servet, Zaragoza, Spain; ${ }^{31}$ H.U. Ramón y Cajal, Madrid, Spain; ${ }^{32}$ H.U. Santa Creu i Sant Pau, Barcelona, Spain; ${ }^{33}$ H.U. Príncipe de Asturias, Madrid, Spain; ${ }^{34}$ H. U. Marqués de Valdecilla, Santander, Spain; ${ }^{35}$ H.U. Donostia, San Sebastián, Spain

Background: Primary Sjögren's syndrome (pSS) is a systemic autoimmune disease characterized by the involvement of the exocrine glands, mainly salivary and lacrimal glands. Approximately half of patients will experience extraglandular complications throughout their evolution.

Objectives: To characterize the involvement of the nervous system (NS) in patients with pSS.

Methods: Multicenter cross-sectional study of a cohort of patients with pSS, constructed by random selection of pSS patients fulfilling the 2002 American-European Consensus Criteria for $\mathrm{pSS}^{1}$ from 33 rheumatology units. Through review of clinical records and interview with patients, demographic, clinical, analytical, therapeutic data and disease activity indexes were collected. Univariate analysis was done by Chi square test, MannWhitney $U$ test and Student's $t$ test. Multivariate analysis was done by linear logistic regression. A $p<0.05$ was considered significant. Patients signed an informed consent. The study was authorized by the ethics committees.

Results: 437 patients were included (95\% women, median age of 58 years). 65 patients developed NS involvement: 26 patients central NS, 31 peripheral NS and 8 both. Multivariate analysis showed association

Disclosure of Interests: Jose Luis Andreu: None declared, Carlos Sánchez-Piedra: None declared, Monica Fernandez Castro: None declared, Victor Martinez Taboada: None declared, Alejandro Olive: None declared, Jose Rosas Consultant for: Abbvie, Amgen, Bristol, Janssen, Lilly, Merck Sharp \& Dohme, Pfizer, UCB Pharma, Speakers bureau: Abbvie, Amgen, Bristol, Janssen, Lilly, Merck Sharp \& Dohme, Pfizer, UCB Pharma, Raúl Menor-Almagro: None declared, Beatriz Rodriguez Lozano: None declared, Ángel García-Aparicio: None declared, Francisco J López-Longo: None declared, Sara Manrique Arija Speakers bureau: ABBvie, MSD, Janssen, Lilly, Roche, Pfyzer, Novartis., Jesús ALberto García Vadillo: None declared, Susana Gil: None declared, Ruth López González: None declared, J. Narváez Consultant for: Bristol-Myers Squibb, Carles Galisteo: None declared, Jorge Juan Gonzalez Martin: None declared, M E Ruiz: None declared, Iñigo Rúa-Figueroa: None declared, Oscar Illera: None declared, Lurdes Romani: None declared, Sheila Melchor: None declared, Begoña Moreira: None declared, Enrique Raya: None declared, Jose M Pego-Reigosa: None declared, Natalia Cid Boza: None declared, Enrique Judez: None declared, Clara Moriano: None declared, Vicente Torrente: None declared, Héctor Corominas: None declared, Blanca Garcia-MagalIon: None declared, Carlos Guillén-Astete: None declared, Ivan Castellví Consultant for: I received fees less than 5000USD as a consultant for Kern and Actelion, Paid instructor for: I received fees less than 2000USD as a instructor for Boehringer -Ingelheim, Novartis and Gebro, Speakers bureau: ND, Cristina Bohórquez: None declared, Javier Loricera: None declared, Joaquín Belzunegui: None declared

DOI: 10.1136/annrheumdis-2019-eular.3607

\section{THU0259 \\ ULTRASOUND OF MAJOR SALIVARY GLANDS IDENTIFIES PATIENTS WITH MORE COMPLEX SALIVARY GLAND HISTOPATHOLOGY BUT NOT MILDER LESIONS}

Chiara Baldini ${ }^{1}$, Francesco Ferro ${ }^{1}$, Nicoletta Luciano ${ }^{1}$, Gianmaria Governato ${ }^{1}$, Marta Mosca ${ }^{1}$, Stefano Bombardieri ${ }^{1}$, Valentina Donati ${ }^{2} .{ }^{1}$ University of Pisa, Department of Clinical and Experimental Medicine, Pisa, Italy; ${ }^{2}$ University of Pisa, Pathology Unit, Pisa, Italy

Background: Ultrasonography of major salivary glands (SGUS) has been proposed as a feasible and reliable tool for the assessment of parotid and submandibular glands inflammation and damage in Sjögren's syndrome (pSS). However, the relationship between major SGUS and labial salivary gland (LSG) histopathology is still unclear.

Objectives: to investigate the correlation between SGUS abnormalities and LSG histopathology in patients newly diagnosed patients with pSS

Methods: Consecutive patients suspected of having pSS were enrolled in this study. All the patients underwent a complete diagnostic work up. The echostructure of each gland on B-mode images was graded on a 5 point scale (0-4), and a SGUS score $\geq 2$ was defined as pathological. Hypo-anechoic areas in the glands were defined as isolated $(<25 \%$ of the surface), localized $(25-50 \%)$ and diffuse-scattered (>50\%). Hyperechoic bands present in more than $50 \%$ of the parenchyma were also recorded. An expert pathologist analyzed all the LGS samples assessing focus score (FS), number of foci and presence of ectopic germinal centers (GCs).

Results: We included 115 pts (105 F: 10 M, mean age (SD) 54.8 (12.5) years). Out of them 51 were diagnosed with pSS and 64 represented the no-SS sicca controls. A SGUS score $\geq 2$ identified pSS patients with a sensitivity of $62.7 \%$ and a specificity of $96.7 \%$. SGUS score significantly correlated with FS $\left(r=0.457^{* *}, p=0.000\right)$, number of foci $\left(r=0.359^{* *}\right.$, $\mathrm{p}=0.000)$ and number of ectopic GCs $\left(r=0.505^{* *}, \mathrm{p}=0.000\right)$. However, the overall concordance between SGUS and LSG histopathology was moderate (Cohen's kappa $=0.574$ ). Thus, we specifically focused on 19/51 pSS "discordant" cases who presented normal SGUS findings but focal lymphocytic sialadenitis in their LSG biopsy. These "discordant" patients tended to present a lower FS $(1.7 \pm 0.5$ vs $2.6 \pm 1.5, \mathrm{p}=0.04)$ and a significantly lower number of foci in their biopsies $(2.7 \pm 1.6$ vs $4.6 \pm 2.9$, 